\section{Chemistry for Schools}

Nuffield Advanced Science. Chemistry. (Penguin: Harmondsworth, Middlesex, 1970. Published for the Nuffield Foundation.) Students' Book II; Topics 13 to 19. Pp. viii +308. £1.00. Teachers' Guide II: Topics 13 to 19 . Pp. 354. $£ 1.50$.

THE recent Black Paper Three contained a remarkable attack by John Bradley of Hull University on the Nuffield O level Chemistry Sample Scheme. The Sample Scheme has many faults, as anyone who has given it an extensive trial can tell, and it is being revised; but, properly used, it gives insight into the key ideas of energy and structure. And my customers seem to prefer it to the older, more historical and descriptive, approach. But then they like to know why they are doing a particular experiment; and, far from being satisfied with mere description, they keep demanding explanations for phenomena until they get one which satisfies them. Bruner's dictum, that any subject can be taught in some intellectually honest form to any child in any stage of development, is very probably true-provided the child has a damn good teacher and the teacher hasn't got too many children. It retains some validity even in the nonideal case of the average teacher with a large class. I have found to my surprise and pleasure that bright thirteen and fourteen year olds can, with the help of a few simple experiments of the type which Bradley calls "advanced and bizarre", readily grasp the essential structural features of plastics.

So far as I know, the Nuffield Advanced Chemistry course has not yet been the target of Bradley's faintly Messianic prose; no doubt it will strike him as even more bizarre. (His Black Paper polemic concludes with St Matthew, 7, verse 9. I retort with verse 19 of the same chapter, as justification for the elimination of methods and ideas which become outdated and unfruitful.) To me, the course seems a logical development of the aims stated in Brian Young's foreword to each of the books: a course which is satisfying and intellectually exciting in itself, with an emphasis on learning rather than being taught, on understanding rather than amassing information, on finding out rather than on being told. In my review of the first batch of the A level chemistry materials (Nature, 228, 786; 1970) I criticized them on two grounds only: cost, and a conceptual intensity which might intimidate the less intellectually able. I'm still sore about the cost; but I'm glad to report that, over the past one and a half terms, we have found all forty-odd of our lower sixth chemists reasonably capable of absorbing the ideas.

This second batch of books maintains the high quality of the first. I was delighted to see, in the Students' Book $I I$, photographs of stamps commemorating Kekule's proposal for the structure of benzene. An excellent brief historical introduction to dyestuffs begins with a quotation from Edmund Burke: "People will not look forward to posterity, who never look backward to their ancestors". (Perhaps this may mollify Bradley?) There is a good summary of acid-base chemistry in the human body. The section on detergents is illustrated by shots of some consequences of the Torrey Canyon disaster, and with one of the River Lee in its full 1961 vintage foam (nicely captioned "One result of the use of detergents with a branched chain alkyl group"). The writing throughout is concise, clear, and stimulating, although not completely free from trivial errors. It is a bit puzzling, though, that all the material on entropy is relegated to the Teachers' Guide: as the Guide states, "It is certainly desirable on general educational grounds that sixth form science students (perhaps all sixth form students?) should have some understanding of entropy". Sure: so why not put something about it in their book? MARTYN BERRY

\section{Hard Men and Hippies}

Varieties of Juvenile Delinquency. By Carl Frankenstein. Pp. xi +252 . (Gordon and Breach: London and New York, December 1970.) £6.00; \$14.50.

MOST psychologists have explained juvenile delinquency in a restricted way by applying psychological or sociological definitions: they either consider the problem to be the result of an interplay of social factors or hold psychic disorders solely responsible. In Varieties of Juvenile Delinquency, Carl Frankenstein analyses several types of delinquency including waywardness, psychopathy and drifting, and compares the causes and symptoms of each, explaining the presence of considerable variation in terms of both structural and socio-economic experiences.

The detailed comparisons of psychopathy and adolescent delinquency are used to show the fallacy of attempting to interpret the problems of adolescence as developmental psychopathy. Although there are superficially some similarities, notably the apparent senselessness of destructive acts, Professor Frankenstein discusses convincingly, and in considerable detail, the differences between the two behavioural categories

A fascinating commentary is also given on the subject of post-war delinquency and the apparent development from the anti-social Teddy Boy type to the asocial drifter of the Hippy cult. From the theme of this study it is hoped that the members of each of the groups will be considered in the light of their individual psychological backgrounds as well as the sociocultural conditions of post-war western society.

The last chapter consists of a selection of most interesting case studies illustrating the various types of delinquent and offering analysis of their problems.

Although the book itself is of an essentially specialist nature, the ideas Frankenstein puts forward will be of value to a much wider group of people who come into contact with the juvenile delinquent and his difficulties.

DianNe WoOdham

\section{Danger in Decibels}

The Effects of Noise on Man. By Karl D. Kryter. (Environmental Sciences: an Interdisciplinary Monograph Series.) Pp. xvii +633 . (Academic: New York and London, October 1970.) £9.10.

DR KRYTER has undertaken a sterling task in writing such a book. The subject matter, although lumped under a common title, ranges through many disciplines; medical, physical and social sciences, together with engineering. It gives the appearance of being a lifetime's accumulation of information. Who will find this book useful? Certainly many people will find sections of the book of great value. The number of graduate students in the UK who can use the book will be quite limited, but even so, it is doubtful if the standard of the text is of adequate depth. The engineer and environmental planner will find only an introduction to the topics of interest, although the bibliography will certainly be useful. The same impression also applies to the research worker.

The dust jacket states that the volume presents a critical and historical analysis of relevant literature. This is certainly true, although the author's bias is clearly detectable, particularly in Part II, "Subjective Responses to Noise". There are places in this section where the author, either in haste or through lack of understanding, doesn't quite explain another worker's results. For example, on page 396 Zepler and Harel did not calculate a unit proportional to Phons (Stevens). On a point of general philosophy, this section of the book lays great emphasis on the conceptual importance of noisiness and its assessor, the perceived noise level. The usefulness of this unit, particularly for assessing the acceptability of sounds produced by fixed wing aircraft, must be acknowledged, but its universality must be carefully questioned. 